\title{
Histopathology Review of Idiopathic Steroid Resistant Nephrotic Syndrome and Outcome in Children in North-West of Iran
}

\author{
Mahtab Rahbar \\ Iran Medical Science University, Tehran, Iran \\ Email: rahbarahbar@gmail.com
}

How to cite this paper: Rahbar, M. (2016) Histopathology Review of Idiopathic Steroid Resistant Nephrotic Syndrome and Outcome in Children in North-West of Iran. Open Journal of Nephrology, 6, 188-199.

http://dx.doi.org/10.4236/ojneph.2016.64024

Received: September 2, 2016

Accepted: December 25, 2016

Published: December 28, 2016

Copyright $\odot 2016$ by author and Scientific Research Publishing Inc. This work is licensed under the Creative Commons Attribution International License (CC BY 4.0).

http://creativecommons.org/licenses/by/4.0/

\section{Abstract}

Introduction: There is currently little information in the literature on the spectrum of histopathologic patterns in children presenting with idiopathic steroid-resistant nephrotic syndrome (iSRNS) in Iran. We conducted to compare the histopathologic distribution of different subtypes' glomerular morphologic patterns in iSRNS and the clinical and biochemical parameters at the time of diagnosis and outcome of patients after immunosuppressive therapy. Material and Methods: This cross sectional study was done in two hundred children, aged 1 - 15 years, who were diagnosed for iSRNS and no response to 4 weeks of standard prednisone therapy $\left(60 \mathrm{mg} / \mathrm{m}^{2} /\right.$ day $)$ referred to nephropathology Department of Emam Reza hospital between 2005 and 2013. Demographic, clinical, laboratory, and histopathological data were retrieved from files and original renal biopsy reports. We discussed histopathologic diagnosis and outcome of iSRNS after initial therapy in patients separately. This study investigated prognostic effects of histopathologic pattern on outcome of iSRNS. Results: The study included 200 children with iSRNS: 141 (70.5\%) were males and 59 (29.5\%) females, with male-to-female ratio of 2.4:1. The mean age was $7.23 \pm 4.37$ years (range: $1-15$ years). Upon pathologic investigation of iSRNS cases, focal segmental glomerulosclerosis (NOS subtype) was the first, with a highest prevalence at a rate of 102/200 (51\%) and MGN was the last, at a rate of 7/200 (3.5\%). Children with iSRNS secondary to MCD are more likely to achieve remission and have better long term prognostic value $(\mathrm{P}<0.00)$. Focal segmental glomerulosclerosis (FSGS) (Tip and Collapse subtypes) is more likely to have worse outcome in response to immunosuppressive therapy $(\mathrm{P}<0.04)$. Conclusions: This study defines the true spectrum of clinicohistopathology patterns underlying iSRNS in children in Northwest of Iran. Also this study shows that the response to cyclosporine can be correlated with the underlying histopathology patterns which have been earned by adequate renal biopsy. 


\section{Keywords}

Idiopathic Nephrotic Syndrome, Steroid-Resistance, Histopathology, Outcome, Child

\section{Introduction}

Idiopathic Steroid-resistant nephrotic syndrome (iSRNS) is a common problem in pediatric nephrology. About $10 \%-20 \%$ of children with nephrotic syndrome have idiopathic steroid resistant nephrotic syndrome (iSRNS) [1] [2] [3] [4]. About 50 percent of patients with iSRNS will progress to end-stage renal disease (ESRD) [3] [5]. It is a point which makes difficult to manage these patients. This study was thus designed to determine the spectrum of histopathological patterns in children presenting with iSRNS at our center. In this way, doing renal biopsy is mandatory to confirm histopathologic pattern of disease. These histological variants of nephrosis may be found alone or in any combination on sequential biopsies in each patient. Therefore, evaluation for iSRNS depends in an adequate renal biopsy to determine the underlying histology. However in the most literatures, primary focal segmental glomerulosclerosis has been reported as the main leading cause indicating poor outcome and warranting more aggressive therapy [6] [7]. Results of studies by the International Study of Kidney Disease in Children (ISKDC) revealed focal and segmental glomerulosclerosis (FSGS), mesengial proliferative glomerulonephritis (MPGN) and minimal change disease (MCD) as the respective morphologic lesions seen in $70 \%, 44 \%$ and $7 \%$ of children with iSRNS. [8]. Also, it demonstrated that clinical corticosteroid response had a high predictive accuracy for outcome than renal histological findings in children with idiopathic nephrotic syndrome [9]. The glomerular morphologic pattern and treatment outcome of iSRNS in Iranian children in North-west of Iran have not been previously defined. In this study, we conducted to compare the histopathologic distribution of different subtypes' glomerular morphologic patterns in iSRNS and outcome of patients after therapy.

\section{Material and Methods}

This is a cross sectional study involving Iranian children with iSRNS who underwent renal needle biopsy under ultrasound guidance were reviewed between June 2005 and December 2013 and followed-up till June 2015. We conducted this study in Iranian children population to include geographic and genetic effects if there are. We discussed clinical manifestations, histopathologic diagnosis, and initial management and outcome of iSRNS in children separately. The inclusion criteria comprised all confirmed cases of iSRNS in patients aged $1-15$ years in adequate specimen. Exclusion criteria were identification of a secondary cause of nephrotic syndrome like namely obesity, drugs, heavy metal exposure, congenital cyanotic heart disease, reflux nephropathy and solitary kidney as well as evidence of CRF with the estimated glomerular filtration rate (eGFR) that 
was persistently $<60 \mathrm{~mL} / \mathrm{min} / 1.73 \mathrm{~m}^{2}$ for at least three months and finally inadequate specimen in renal biopsy. Also what things that made important limitation in our study were incomplete data records and inadequate biopsy specimen. The diagnostic criteria for the nephrotic syndrome (NS) were edema, plasma albumin $<25 \mathrm{~g} / \mathrm{L}$, and severe proteinuria $>40 \mathrm{mg} / \mathrm{m}^{2} /$ hour or a urinary protein/creatinine ratio (UPCR) $>200 \mathrm{mg} /$ mmol [10], by quantitative assessment or dipstick proteinuria $>300 \mathrm{mg} / \mathrm{dL}$. iSRNS was diagnosed based on combination of 1) absence of a specific etiology for the NS, and 2) failure to achieve complete remission (CR) using the ISKDC treatment protocol for initial therapy of NS; the latter comprised prednisone $60 \mathrm{mg} / \mathrm{m}^{2} /$ day for four weeks, followed by $40 \mathrm{mg} / \mathrm{m}^{2} / 48$ hours for another four weeks [3] [11]; prednisolone was used in our patients. CR was defined as proteinuria $<4 \mathrm{mg} / \mathrm{m}^{2} /$ hour or UPCR $<20 \mathrm{mg} / \mathrm{mmol}$ or dipstick proteinuria $<30 \mathrm{mg} / \mathrm{dl}$ tested on three consecutive days [10]. Remission was regarded as sustained if no relapse occurred for at least six months. Mild to moderate proteinuria (MMP) or partial remission was defined as proteinuria of $4-39 \mathrm{mg} / \mathrm{m}^{2}$ / hour or a UPCR of $20-199 \mathrm{mg} / \mathrm{mmol}$ or $30-100 \mathrm{mg} / \mathrm{dL}$ by dipstick. Relapse was defined as recrudescence of proteinuria in excess of $40 \mathrm{mg} / \mathrm{m}^{2} /$ hour or UPCR $>200 \mathrm{mg} /$ $\mathrm{mmol}$ or $>100 \mathrm{mg} / \mathrm{dL}$ by dipstick for three consecutive days after an initial CR. Steroid resistance (SR)was failure to achieve CR following at least four weeks of prednisolone $\left(60 \mathrm{mg} / \mathrm{m}^{2} /\right.$ day) treatment. Patients who had an initial CR but later developed frequent relapses followed by steroid dependence before finally becoming steroid resistant were diagnosed as secondary SR while those who failed to respond to at least four weeks of steroid treatment were classified primary SR. Each patient was evaluated for gender, age at onset of NS, age at diagnosis, vital signs, anthropometry and presence of hypertension (HTN), oliguria and laboratory data. HTN was defined according to the update on the 1987 Task Force Report on High Blood Pressure in Children and Adolescents [11]. Treatment protocol used, treatment complications, co-morbidities, time to remission, remission duration, admission duration, follow-up and outcome were evaluated. Renal biopsy was performed after a diagnosis of steroid resistance and before immunosuppressive treatment. All children underwent renal needle biopsy under ultrasound guidance after obtaining appropriate informed consent.

Microscopic glomerular features were defined along standard lines [12] [13] [14]. Tissue sections were not greater than three microns in thickness. Three cores of native renal biopsy were routinely obtained for evaluation by light microscopy, Immunofluorescence and electron microscopy. Twenty-five or more glomeruli per renal tissue specimen were regarded as adequate for reporting. Biopsy specimens were processed using standard procedures that included hematoxylin-eosin, periodic acid-Schiff, Jones and green Masson straining of formalin-included pieces; Immunofluorescence of frozen samples were carried out with a panel of antiserum protein antibodies against $\operatorname{Ig} \mathrm{A}, \operatorname{IgM}$, IgG, C3, C1q, C4 and fibrinogen. Tissue samples for EM were processed as described in our previous report [15]. Briefly, EM tissue was fixed in $4 \%$ glutaraldehyde, post fixed in $1 \%$ osmium tetroxide at $0.02 \mathrm{M}$ Sorenson Phosphate buffer at $\mathrm{pH} 7.4$, processed for EM, and embedded in Eponate resin. Ultra-thin sections $(100 \mathrm{~nm})$ were cut on Leica 
ultra-microtome. Sections were stained on copper 300-mesh girds with Uranyl acetate and Lead citrate and examined with a JEM 1200 EX II electron microscope. The biopsy specimens were reviewed and interpreted by the two pathologists. We adopted the protocol treatment established by the French Society of Pediatric Nephrology [16]. Cyclosporine was given to all patients at an oral initial dose of $150-200 \mathrm{mg} / \mathrm{m} 2$ body surface area per day (not exceeding $200 \mathrm{mg} / \mathrm{m}^{2}$ per day) in two equal doses. The dosage was adjusted to obtain trough concentrations between 100 and $150 \mathrm{ng} / \mathrm{ml}$ as measured by the monoclonal antibody radioimmunoassay on whole blood before the morning taking. Prednisone was administered at a single dose of $30 \mathrm{mg} / \mathrm{m}^{2}$ per day during the first month and on alternate days for 5 months. About 50 percent of patients with iSRNS will progress to end-stage renal disease (ESRD) [3] [5]. The goals of therapy for iSRNS are to achieve complete resolution of proteinuria, thereby reducing the complications associated with NS, and preservation of kidney function. However, there is no currently optimal therapy for iSRNS that consistently meets these two goals. The therapeutic response was assessed 4 months after starting treatment protocol. In patients who had not achieved complete or partial remission, the therapeutic regimen was stopped.

The local ethics committee approved the study.

\section{Statistical Analysis}

All values are given as mean standard deviation. The statistical analysis was performed by the SPSS 14.0 statistical analysis software (Chicago, Ill, USA). Outcome was evaluated in terms of partial/complete remission versus no remission. The results were analyzed for their statistical significance using Student's test for continuous variables and chi square test for discrete variables; $\mathrm{P}<0.005$ was considered significant.

\section{Results}

The study included 200 children with idiopathic steroid-resistant nephrotic syndrome. Mean age at diagnosis of steroid resistance was $7.23 \pm 4.37$ years with a range of $1-15$ years. The male-to-female ratio was 2.4:1. Demographic Details regarding age and sex distribution are presented in Table 1.

The most common presenting symptoms are first limb edema and then facial edema which is more present in FSGS group especially in Tip subtype (Table 1). Seventy nine patients (39.5\%) had an initial steroid-resistance, while hundred twenty three patients (61.5\%) had a late steroid-resistance. Mean serum albumin and creatinine were $2.46 \pm$ $0.54 \mathrm{~g} / \mathrm{dl}$ and $0.84 \pm 0.43 \mathrm{mg} / \mathrm{dl}$ respectively. All patients underwent a renal biopsy which was studied by light microscopy and Immunofluorescence and electron microscopy. The mean number of glomeruli studied was 27 (range 25 - 36). Pathologic examination revealed minimal change disease (MCD) at rate of $29 \%$, Focal segmental glomerulosclerosis (FSGS) at a rate of $51 \%$ with different subtypes (Figure 1), Mesengial Proliferative GN (MPGN) at a rate of $14 \%$ and membranous GN (MGN) at rate of $6 \%$ (Figure 2). Focal segmental glomerulosclerosis (NOS subtype) was the most common 
Table 1. Demographic, clinical features in different histopathological groups and comparative results.

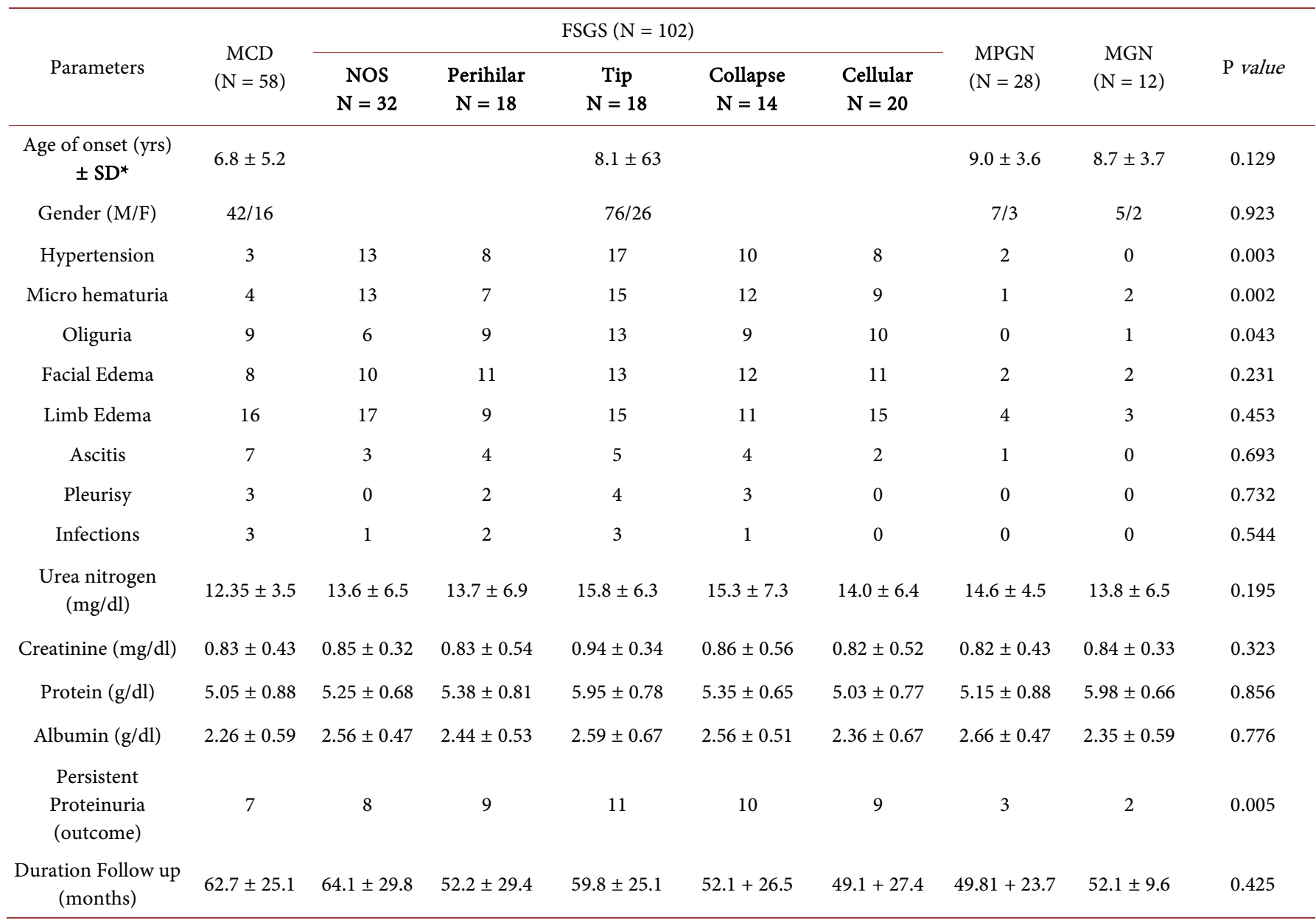

${ }^{*}$ Data expressed as mean \pm SD, MCD: minimal change disease, FSGS: focal segmental glomerulosclerosis, MPGN: mesengial proliferative glomerulonephritis, MGN: membranous glomerulonephritis.

histopathological pattern and minimal change disease (MCD) was the second histological pattern which was found in 58 patients (29\%).

In children aged more than 7 years, FSGS was the most common histopathological subgroup. In children aged less than 6 years, MCD was the most common subgroup. Among 70 patients with hypertension, 56 had a FSGS. Gross hematuria was not observed in all patients. In the MCD group, 7\% patients had micro hematuria, only 5\% patients had hypertension and $15.5 \%$ had oliguria. In 55\% patients with FSGS (Tip and then Collapse subtypes) had hypertension and also micro hematuria and $46 \%$ had oliguria. The therapeutic response to cyclosporine prednisone combination was assessed 4 months after starting the treatment protocol. 22 patients $(11 \%)$ showed no response to the therapy. 128 patients (64\%) achieved complete remission. Partial remission was achieved in 50 patients (25\%). So, overall response (complete or partial remission) regardless of pathological types is $89 \%$. The remission was achieved during the first month of treatment in $25.28 \%$ of patients, during the second month in $29.77 \%$ of patients, during the third month in $27.52 \%$ and during the fourth month in $17.41 \%$. Also, 


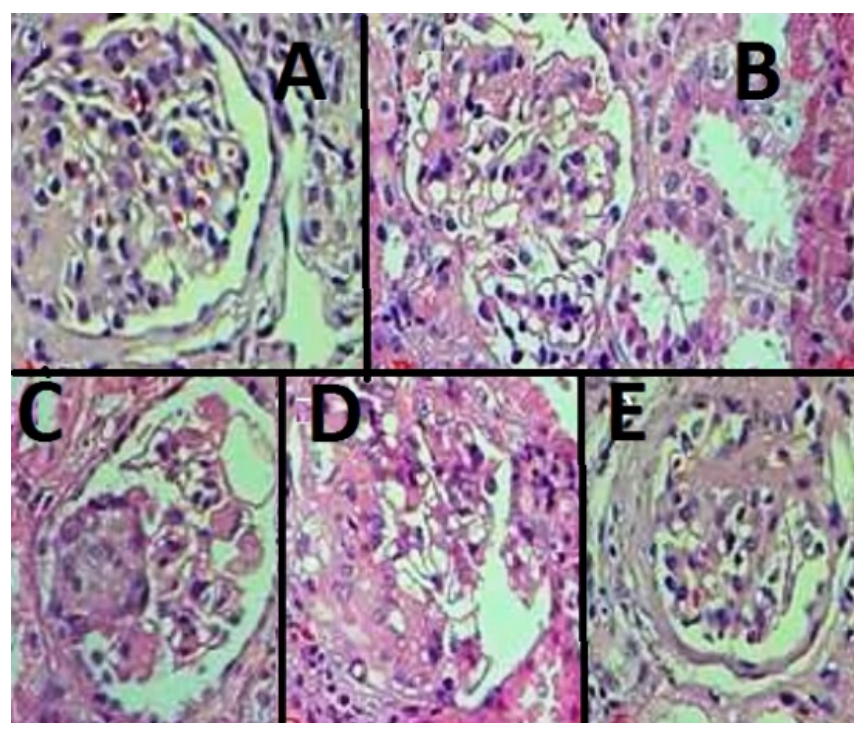

Figure1. Medium-power view showing a glomerulus with segmental scarring associated with adhesion formation with Bowman's capsule in different subtypes, in a case of classic focal segmental glomerulosclerosis. (H \& E stain $\times 200$ ). Cellular type FSGS (A), NOS type FSGS (B), Tip type FSGS (C), Collapse type FSGS (D), Perihilar Type FSGS (E).

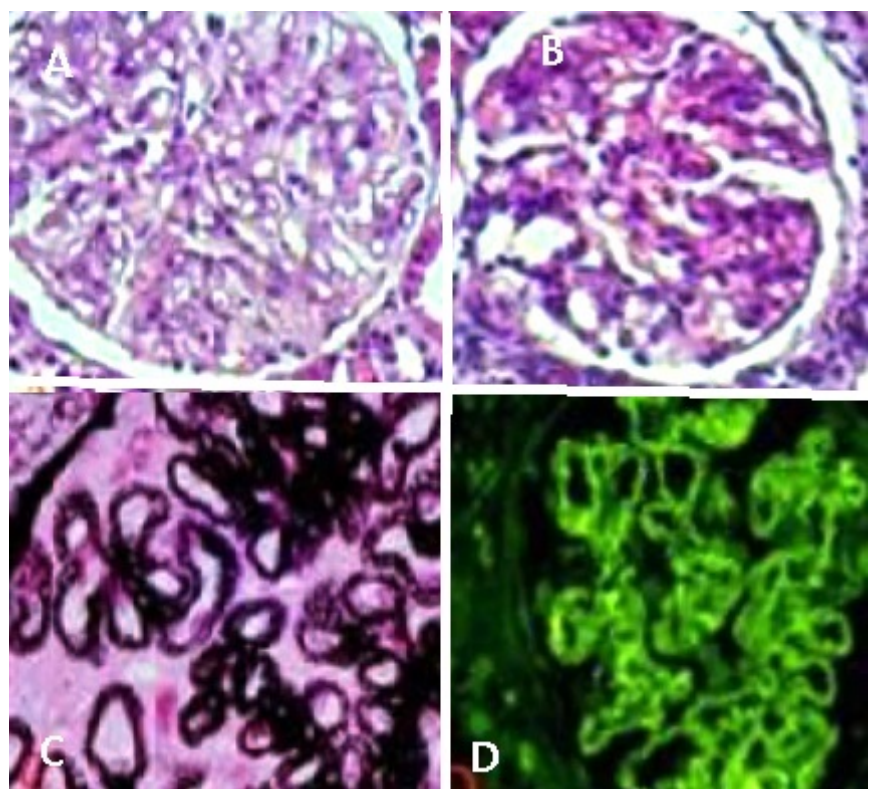

Figure 2. Medium power view of a representative section of a renal biopsy with significant mesangial proliferation in MPGN in $\mathrm{H}$ \& $\mathrm{E}$ stain (A) and glomerule with thick base membrane in PAS stain (B) and in Jones stain (C) with IgG deposit in granular pattern in IF stain $(\times 100)$.

the response to treatment was analyzed according to pathological type. We found a statistically significant relationship between the different pathological types and the re- 
sponse to cyclosporine-prednisone. Children with iSRNS secondary to MCD are more likely to achieve remission and have better long term prognostic value compare to FSGS (NOS subtypes) which is more likely to have primary response to immunosuppressive therapy $(\mathrm{P}<0.04)$. In contrast to MGN which is less likely to achieve remission but was not significant $(\mathrm{P}<0.967)$. There is no significant correlation between the response to cyclosporine and age, sex (Table 2). Moreover, the rate of remission is the same in patients with initial or late steroid-resistance.

\section{Discussion}

Idiopathic nephrotic syndrome is one of the commonly glomerular diseases in children. Most patients are steroid sensitive and respond to the therapy with remission of proteinuria [16] [17]. Approximately $10 \%$ of children with nephrotic syndrome, who do not respond to corticosteroids, are qualified as steroid resistant [18]. This is one of the largest studies on the spectrum of histopathological lesions underlying iSRNS in children from a single center located in the northwest of Iran. In this research study we have tried to present the true pattern of glomerulopathies in children who suffering from iSRNS in this part of the world [19] [20]. More recent evidence suggests that the histopathological spectrum of glomerulopathies underlying iSRNS is changing in both adults

Table 2. Therapeutic response to cyclosporine according to age, sex, clinical presentation and histopathologic types. ${ }^{\star}$ PSR: primary steroid resistant, ${ }^{\star *}$ SSR: secondary steroid resistance.

\begin{tabular}{|c|c|c|c|c|}
\hline \multirow{2}{*}{\multicolumn{2}{|c|}{ parameters }} & \multicolumn{2}{|c|}{ Response to cyclosporine } & \multirow[b]{2}{*}{$\mathrm{P}$ value } \\
\hline & & \multirow{2}{*}{$\begin{array}{c}\text { Responders } \\
\mathrm{n}=178(89 \%)\end{array}$} & $\begin{array}{c}\text { Non responders } \\
n=22(11 \%)\end{array}$ & \\
\hline \multicolumn{2}{|l|}{ Age (months) } & & $94(43-116)$ & 0.785 \\
\hline \multirow{2}{*}{\multicolumn{2}{|c|}{$\begin{array}{l}\text { Male } \\
\text { Female }\end{array}$}} & $166(83 \%)$ & $12(6 \%)$ & \multirow{2}{*}{0.645} \\
\hline & & $49(24.5 \%)$ & $10(5 \%)$ & \\
\hline \multirow{2}{*}{$\begin{array}{c}\text { Steroid } \\
\text { Resistance }\end{array}$} & & \multirow{2}{*}{$178(89 \%)$} & ${ }^{\star} \operatorname{PSR} 9(4.5 \%)$ & 0.002 \\
\hline & & & ${ }^{*} \operatorname{SSR} 13(5.5 \%)$ & 0.004 \\
\hline \multicolumn{2}{|c|}{ MCD } & $54(27 \%)$ & SSR $4(2 \%)$ & 0.002 \\
\hline \multirow{6}{*}{$\begin{array}{l}\text { Histology } \\
\text { subtype }\end{array}$} & NOS & $32(16 \%)$ & PRS 24 (12\%) & 0.004 \\
\hline & Hilar & $18(8 \%)$ & PSR $1(0.5 \%)$ & 0.002 \\
\hline & Tip & $18(8 \%)$ & PSR $2(1 \%)$ & 0.005 \\
\hline & \multirow{2}{*}{$\mathrm{Col}$} & \multirow{2}{*}{$14(4.5 \%)$} & PSR $3(1.75 \%)$ & \multirow{2}{*}{0.376} \\
\hline & & & SSR $2(0.75 \%)$ & \\
\hline & Cell & $20(9.5 \%)$ & SRS $2(1 \%)$ & 0.45 \\
\hline \multirow{2}{*}{\multicolumn{2}{|c|}{ MPGN }} & $28(14 \%)$ & SSR $14(7 \%)$ & \multirow{2}{*}{0.548} \\
\hline & & $20(1470)$ & PSR 14 (7\%) & \\
\hline \multirow{2}{*}{\multicolumn{2}{|c|}{ MGN }} & $6(30)$ & SSR $10(5 \%)$ & \multirow{2}{*}{0.967} \\
\hline & & & PSR 2 (1\%) & \\
\hline
\end{tabular}

MCD: minimal change disease, FSGS: focal segmental glomerulosclerosis, MPGN: mesangial proliferative glomerulonephritis, MGN: membranous glomerulonephritis. 
and children [21] [22]. Despite the absence of evidence based recommendations regarding the role of renal biopsy in these patients, this procedure provides important information on renal histology and outcome [23]. However, renal biopsy remains necessary to establish a long-term prognosis since the evolution towards ESRD is seen especially with FSGS [24]. Earlier reports believed that the outcome of the disease can be predicted from the clinical response to steroids, and the biopsy is unnecessary for a vast preponderance of children with iSRNS [9]. Many authors have found a rise in the prevalence of FSGS in children during the recent past, and since this lesion is associated with a significantly lower response to steroids than MCD, it is recommended to detect its presence on renal biopsy in order to better inform the patients about the long-term prognosis. These authors also recommend a renal biopsy before potentially nephrotoxic drugs, such as Cyclosporine are started [15] [25] [26] [27]. The renal histology in iSRNS is different, with $30 \%-40 \%$ patients each showing minimal change disease and FSGS, and a smaller group with diffuse mesengial proliferation [28].

The results of our study are generally similar to those previously reported in the literature. All the previously reported studies have observed a higher prevalence of FSGS in this form of iSRNS [29] [30]. But the rates of FSGS diagnosis are not uniform across the world, however. In study from India, Gultai et al. reported FSGS in 50\%, the same as our finding [26]. In Saudi Arabia, a country comparable to our and in Tunisia, the incidence of FSGS is more important than MCD [31]. Javaherian et al. [32] reported that in Iran, FSGS came in first, with the highest prevalence at a rate of $32.4 \%$, and MGN came in last, at a rate of 5.6\% (range $1-14$ years). Three studies, respectively, from Japan [33] and France [34] reported a significantly higher incidence of MCD compared to FSGS. In Egyptian children, mesengial hypercellularity and IgA nephropathy might be the major causes for steroid resistance [35]. The reasons for disparities in the prevalence of MCD and FSGS are not entirely clear. They are probably explained by racial, genetic and environmental factors [15]-[26]. Moreover, slight differences in disease definitions, inclusion criteria and numbers of patients who participated in each study may be partly responsible. One important factor, which should also be considered, is that of observer variation in the reporting of renal lesions, especially of MCD, mesengial proliferative and sclerosis with early FSGS [36]. The lesions of early FSGS may be missed easily if not enough glomeruli in each specimen or fragmented sections of the renal biopsy. Furthermore, examination of renal histology in FSGS reveals a variety of histological subtypes, with variable response to therapy and outcome [37] [38]. Follow up the non-FSGS patients with repeat biopsy might show morphological transition with FSGS patients. Thus, these histological conditions may be found alone or in combination on sequential biopsies in the same patient. It's happen that in several documented studies, the diagnosis of MCD patient change to FSGS in a follow-up biopsy specimen. This has led to the conclusion that MCD and FSGS may represent a continuum of the same process [38]. All our biopsies were examined by trained renal pathologists with vastwork and research experience. Children who fail to respond to oral steroids must be treated with immunosuppressive agents in addition to steroids [39]. A combination of 
oral prednisolone and oral cyclosporine may reach to remission in children [40]. We found that response to this therapy protocol was initially correlated by renal histology; patients with minimal change nephrotic syndrome show better response to this therapy protocol, while FSGS especially Tip and Collapse subtypes and then other subgroups like MGN, MPGN and MGN show unsatisfactory respond to therapy and outcome.

However, in recent studies, this correlation is not always established. It seems that the response rate is similar whatever FSGS histological subtype [40] [41]. Hymes found that the overall response to cyclosporine is very similar in non-FSGS histological types [37]. However, the rate of complete remission is frequently observed during the MCD. Niaudet obtained a poorer response in patients with FSGS compared with those with MCD (51.5\% vs. 40\%) [16]. Hamasaki et al. and associates have reported that high rate of remission in patients with FSGS (85.7\%) have been earned by administration of methylprednisolone pulse, in addition to cyclosporine [39].

\section{Conclusion}

In conclusion, our study defines the true spectrum of clinicohistopathology patterns underlying iSRNS in children in Northwest of Iran. Also, it indicates that FSGS is the predominant pattern in children with iSRNS, followed by MCD, MPGN and MGN. This study shows that the response to cyclosporine can be correlated with the underlying pathological lesion. Therefore, a renal biopsy should be the first step before initiating treatment with potentially nephrotoxic agents.

\section{References}

[1] McKinney, P.A., Feltbower, R.G., Brocklebank, J.T. and Fitzpatrick, M.M. (2001) Time Trends and Ethnic Patterns of Childhood Nephritic Syndrome in Yorkshire, UK. Pediatric Nephrology, 16, 1040-1044. https://doi.org/10.1007/s004670100021

[2] Wong, W. (2007) Idiopathic Nephrotic Syndrome in New Zealand Children, Demographic, Clinical Features, Initial Management and Outcome after Twelvemonth Follow-Up: Results of a Three-Year National Surveillance Study. Journal of Paediatrics and Child Health, 43, 337-341. https://doi.org/10.1111/j.1440-1754.2007.01077.x

[3] Habashy, D., Hodson, E.M. and Craig, J.C. (2003) Interventions for Steroid Resistant Nephrotic Syndrome: A Systematic Review. Pediatric Nephrology, 18, 906-912. https://doi.org/10.1007/s00467-003-1207-0

[4] Kim, J.S., Bellew, C.A., Silverstein, D.M., Aviles, D.H., Boineau, F.G. and Vehaskari, V.M. (2005) High Incidence of Initial and Late Steroid Resistance in Childhood Nephrotic Syndrome. Kidney International, 68, 127581. https://doi.org/10.1111/j.1523-1755.2005.00524.x

[5] Ehrich, J.H., Geerlings, C., Zivicnjak, M., et al. (2007) Steroid-Resistant Idiopathic Childhood Nephrosis: Over Diagnosed and Undertreated. Nephrology Dialysis Transplantation, 22, 2183. https://doi.org/10.1093/ndt/gfm092

[6] Borges, F.F., Shiraichi, L., Da Silva, M.P., Nishimoto, E.I. and Nougueira, P.C. (2007) Is Focal Segmental Glomerulosclrrosis Increasing in patients with Nephritic Syndrome? Pediatric Nephrology, 22, 1309-1313. https://doi.org/10.1007/s00467-007-0516-0

[7] Kirpekar, R., Yorgin, P.D., Tune, B.M., Kim, M.K. and Sibley, R.K. (2002) Clinicopathologic Correlates Predict the Outcome in Children with Steroid-Resistant Idiopathic Nephrotic 
Syndrome Treated with Pulse Methylprednisolone Therapy. American Journal of Kidney Diseases, 39, 1143-1152. https://doi.org/10.1053/ajkd.2002.33382

[8] International Study of Kidney Disease in Children (1981) The Primary Nephrotic Syndrome in Children. Identification of Patients with Minimal Change Nephrotic Syndrome from Initial Response to Prednisone. A Report of the International Study of Kidney Disease in Children. The Journal of Pediatrics, 98, 561-564.

https://doi.org/10.1016/S0022-3476(81)80760-3

[9] International Study of Kidney Disease in Children (1978) Nephrotic Syndrome in Children: Prediction of Histopathology from Clinical and Laboratory Characteristics at Time of Diagnosis. Kidney International, 13, 159-165. https://doi.org/10.1038/ki.1978.23

[10] Report of a Workshop by the British Association for Paediatric Nephrology and Research Unit, Royal College of Physicians (1994) Consensus Statement on Management and Audit Potential for Steroid Responsive Nephrotic Syndrome. Archives of Disease in Childhood, 70, 151-157. https://doi.org/10.1136/adc.70.2.151

[11] National High Blood Pressure Education Programme Working Group on Hypertension Control in Children and Adolescents (1996) Update on the 1987 Task Force Report on High Blood Pressure in Children and Adolescents. Pediatrics, 98, 649-658.

[12] Olson, J.L. and Schwartz, M.M. (1998) The Nephrotic Syndrome: Minimal Change Disease, Focal Segmental Glomerulosclerosis, and Miscellaneous Causes. In: Jennette, J.C., Olson, J.L., Schwartz, M.M. and Silva, F.G., Eds., Heptinstall s Pathology of the Kidney, LippincottRaven Publishers, Philadelphia, 187-257.

[13] Silva, F.G. (1998) Membranoproliferative Glomerulonephritis. In: Jennette, J.C., Olson, J.L., Schwartz, M.M. and Silva, F.G., Eds., Heptinstall s Pathology of the Kidney, LippincottRaven Publishers, Philadelphia, 309-368.

[14] Schwartz, M.M. (1998) Membranous Glomerulonephritis. In: Jennette, J.C., Olson, J.L., Schwartz, M.M. and Silva, F.G., Eds., Heptinstall s Pathology of the Kidney, LippincottRaven Publishers, Philadelphia, 259-307.

[15] Mubarak, M., Lanewala, A., Kazi, J.I., Akhter, F., Sher, A., Fayyaz, A. and Bhatti, S. (2009) Histopathological Spectrum of Childhood Nephrotic Syndrome in Pakistan. Clinical and Experimental Nephrology, 13, 589-593. https://doi.org/10.1007/s10157-009-0216-0

[16] Niaudet, P. (1994) Treatment of Childhood Steroid-Resistant Idiopathic Nephrosis with a Combination of Cyclosporine and Prednisone. Journal of Pediatrics, 125, 981-986. https://doi.org/10.1016/S0022-3476(05)82020-7

[17] Fujinaga, S., Kaneko, K., Muto, T., Ohtomo, Y., Murakami, H. and Yamashiro, Y. (2006) Independent Risk Factors for Chronic Cyclosporine Induced Nephropathy in Children with Nephrotic Syndrome. Archives of Disease in Childhood, 91, 666-670. https://doi.org/10.1136/adc.2005.080960

[18] Brodehl, J. (1991) The Treatment of Minimal Change Nephrotic Syndrome: Lessons Learned from Multicenter Cooperative Studies. European Journal of Pediatrics, 150, 380-387. https://doi.org/10.1007/BF02093714

[19] Rahbar, M. (2009) Kidney Biopsy in West of Iran: Complications and Histopathological Findings. Indian Journal of Nephrology, 19, 68-70. https://doi.org/10.4103/0971-4065.53325

[20] Mardanpour, K. and Rahbar, M. (2013) Histopathologic Patterns of Adult Renal Disease in Kermanshah, Iran: A 6-Year Review of Two Referral Centers. Caspian Journal of Internal Medicine, 4, 717-721.

[21] Bonilla-Felix, M., Parra, C., Dajani, T., Ferris, M., Swinford, R.D., Portman, R.J. and Verani, R. (1999) Changing Patterns in the Histopathology of Idiopathic Nephrotic Syndrome in 
Children. Kidney International, 55, 1885-1890.

https://doi.org/10.1046/j.1523-1755.1999.00408.x

[22] Kari, J.A. (2002) Changing Trends of Histopathology in Childhood Nephrotic Syndrome in Western Saudi Arabia. Saudi Medical Journal, 23, 317-321.

[23] Nammalwar, B.R., Vijayakumar, M. and Prahlad, N. (2006) Experience of Renal Biopsy in Children with Nephrotic Syndrome. Pediatric Nephrology, 21, 286-288. https://doi.org/10.1007/s00467-005-2084-5

[24] Fuentes, G.M., Mesequer, C.G., Carrion, A.P., Garcia-Pose, A., Hijosa, M.M., Garcia-Pose, A., Melgar, A.A. and Torres, M.N. (2010) Long-Term Outcome of Focal Segmental Glomerulosclerosis after Pediatric Renal Transplantation. Pediatric Nephrology, 25, 529-534. https://doi.org/10.1007/s00467-009-1361-0

[25] Kitiyakara, C., Kopp, J.B. and Eggers, P. (2003) Trends in the Epidemiology of Focal Segmental Glomerulosclerosis. Seminars in Nephrology, 23, 172-182.

https://doi.org/10.1053/snep.2003.50025

[26] Gulati, S., Sengupta, D., Sharma, R.K., Sharma, A., Gupta, R.K., Singh, U., et al. (2006) Steroid Resistant Nephrotic Syndrome: Role of Histopathology. Indian Pediatrics, 43, 55-60.

[27] Azhar, A., Ikram, M. and Amer, S. (2011) Histological Pattern of Steroid Resistant Nephrotic Syndrome in Children: A Single Center Study. Journal of Medical Sciences, 19, 98-101.

[28] Hamasaki, Y., Yoshikawa, N., Hattori, S., Sasaki, S., Iijima, K., Nakanishi, K., et al. (2009) Cyclosporine and Steroid Therapy in Children with Steroid-Resistant Nephrotic Syndrome. Pediatric Nephrology, 24, 2177-2185. https://doi.org/10.1007/s00467-009-1264-0

[29] Olowu, W.A., Adelusola, K.A. and Adefehinti, O. (2010) Childhood Idiopathic Steroid Resistant Nephrotic Syndrome in Southwestern Nigeria. Saudi Journal of Kidney Diseases and Transplantation, 21, 979-990.

[30] Kari, J.A., Halawani, M., Mokhtar, G., Jalalah, S.M. and Anshasi, W. (2009) Pattern of Steroid Resistant Nephrotic Syndrome in Children Living in the Kingdom of Saudi Arabia: A Single Center Study. Saudi Journal of Kidney Diseases and Transplantation, 20, 854-857.

[31] Mekahli, D., Liutkus, A., Ranchin, B., Yu, A., Bessenay, L., Girardin, E., et al. (2009) Long-Term Outcome of Idiopathic Steroid-Resistant Nephrotic Syndrome: A Multicenter Study. Pediatric Nephrology, 24, 1525-1532. https://doi.org/10.1007/s00467-009-1138-5

[32] Javadilarijani, F., Ahmadpanah, A., Javadilarijani, F., Seddigh, L., Movahhed, S.M.M., Arefi, M., et al. (2015) Histopathologic Characteristics of Steroid-Resistant Nephrotic Syndrome in Children in Iran. Journal of Pediatric Nephrology, 3, 100-103.

[33] Thomas, D.B., Franceschini, N., Hogan, S.L., ten Holder, S., Jennette, C.E., Falk, R.J., et al. (2006) Clinical and Pathological Characteristics of Focal Segmental Glomerulosclerosis Pathologic Variants. Kidney International, 69, 920-926. https://doi.org/10.1038/sj.ki.5000160

[34] Otukesh, H., Otukesh, S., Mojtahedzadeh, M., Hoseini, R., Fereshtehnejad, S.M., Riahi Fard, A., et al. (2009) Management and Outcome of Steroid-Resistant Nephrotic Syndrome in Children. Iranian Journal of Kidney Diseases, 3, 210-217.

[35] Elham Ibrahim, S., Eman Abdel-Salam, I., Nadia Galal, E. and Manal Ibrahim, S. (2013) Histological Patterns of Idiopathic Steroid Resistant Nephrotic Syndrome in Egyptian Children: A Single Center Study. Journal of Nephropathology, 2, 53-60. https://doi.org/10.5812/nephropathol.8997

[36] Gargah, T., Labassi, A., Goucha-Louzir, R., Moussa, F.B. and Lakhoua, M.R. (2011) Histopathological Spectrum of Childhood Idiopathic Steroid-Resistant Nephrotic Syndrome in Tunisia. Tunisie Medicale, 89, 258-261.

[37] International Study of Kidney Disease in Children (1981) Primary Nephrotic Syndrome in 
Children: Clinical Significance of Histopathologic Variants of Minimal Change and of Diffuse Mesengial Hypercellularity. Kidney International, 20, 765-771.

https://doi.org/10.1038/ki.1981.209

[38] Hoyer, P., Vester, U. and Becker, J.U. (2008) Steroid Resistant Nephrotic Syndrome. In: Schaefer, G.D., Comprehensive Pediatric Nephrology, Mosby Elsevier, Philadelphia, 257267.

[39] Hymes, L.C. (1995) Steroid-Resistant, Cyclosporine-Responsive, Relapsing Nephrotic Syndrome. Pediatric Nephrology, 9, 137-139. https://doi.org/10.1007/BF00860726

[40] Abeyagunawardena, A.S., Sebire, N.J., Risdon, R.A., Dillon, M.J., Rees, L., Van't Hoff, W., et al. (2007) Predictors of Long-Term Outcome of Children with Idiopathic Focal Segmental Glomerulosclerosis. Pediatric Nephrology, 22, 215-221.

[41] Nickavar, A. and Rahbar, M. (2016) A Clinicopathologic Study of Children with Idiopathic Focal Segmental Glomerulosclerosis. Fetal and Pediatric Pathology, 35, 159-166.

https://doi.org/10.3109/15513815.2016.1153177

\section{Submit or recommend next manuscript to SCIRP and we will provide best service} for you:

Accepting pre-submission inquiries through Email, Facebook, LinkedIn, Twitter, etc. A wide selection of journals (inclusive of 9 subjects, more than 200 journals)

Providing 24-hour high-quality service

User-friendly online submission system

Fair and swift peer-review system

Efficient typesetting and proofreading procedure

Display of the result of downloads and visits, as well as the number of cited articles Maximum dissemination of your research work

Submit your manuscript at: http://papersubmission.scirp.org/

Or contact ojneph@scirp.org 